\title{
Short communication: Measurements of methane emissions from feed samples in filter bags or dispersed in the medium in an in vitro gas production system
}

\author{
M. Ramin, ${ }^{* 1}$ S. J. Krizsan, ${ }^{*}$ F. Jančík, † and P. Huhtanen* \\ *Swedish University of Agricultural Sciences, Department of Agricultural Research for Northern Sweden, S-901 83 Umeå, Sweden \\ †Institute of Animal Science, Prague-Uhříněves, Přátelství 815, 10400 Prague, Czech Republic
}

\begin{abstract}
The objective of this study was to compare methane $\left(\mathrm{CH}_{4}\right)$ emissions from different feeds when incubated within filter bags for in vitro analysis or directly dispersed in the medium in an automated gas in vitro system. Four different concentrates and 4 forages were used in this study. Two lactating Swedish Red cows were used for the collection of rumen fluid. Feed samples were milled to pass a $1.0-\mathrm{mm}$ screen. Aliquots $(0.5 \mathrm{~g})$ of samples were weighed directly in the bottles or within the F57 filter bags that were placed in the bottles. Gas samples were taken during 24 and $48 \mathrm{~h}$ of incubation, and $\mathrm{CH}_{4}$ concentration was determined. The data were analyzed using a general linear model. Feeds differed significantly in $\mathrm{CH}_{4}$ emission both at 24 and at $48 \mathrm{~h}$ of incubation. The interaction between feed and method on methane emission in vitro was significant, indicating that the ranking of feeds was not consistent between the methods. Generally, greater amounts of $\mathrm{CH}_{4}$ were emitted from samples directly dispersed in the medium compared with those incubated within the filter bags, which could be a result of lower microbial activity within the filter bags. The ratio of $\mathrm{CH}_{4}$ to total gas was greater when the feeds were incubated within bags compared with samples directly dispersed in the medium. Incubating samples in filter bags during $48 \mathrm{~h}$ of incubation cannot be recommended for determination of $\mathrm{CH}_{4}$ emission of feeds in vitro.
\end{abstract}

Key words: filter bag, gas production, in vitro, methane emission

\section{Short Communication}

Methane $\left(\mathrm{CH}_{4}\right)$ is the greenhouse gas that has recently been subject to most attention with regard to the environmental impact of different ruminant livestock production systems (Cederberg et al., 2013). Dietary

Received January 8, 2013.

Accepted March 7, 2013.

${ }^{1}$ Corresponding author: mohammad.ramin@slu.se and animal factors considerably influence methane emissions from ruminants (Ramin and Huhtanen, 2013). Methane is produced as a result of microbial breakdown of carbohydrates in the rumen and it represents an energy loss of 0.02 to 0.12 of gross energy intake to the animal (Johnson and Johnson, 1995). Recently, in vitro methods have been applied to evaluate the effects of diet composition and feed additives on $\mathrm{CH}_{4}$ emissions (Becker and van Wikselaar, 2011; Opsi et al., 2012; Sakthivel et al., 2012). The feed samples incubated in vitro can be enclosed in filter bags for fiber and in vitro studies (F57 bags, Ankom Technology Corp., Macedon, NY) or directly dispersed in the in vitro medium. Incubating feeds in filter bags makes simultaneous determination of in vitro digestibility easier by applying fewer transfers of sample residues after incubation, but also seems to be less accurate compared with in vivo degradability (Krizsan et al., 2013). However, bags can restrict microbial digestion, particles can be lost from the bags during incubation, and the bag can act as a physical hindrance for removal of end products from the degradation (Nozière and Michalet-Doreau, 2000). We hypothesized that $\mathrm{CH}_{4}$ emission in vitro could be lower if samples are incubated within filter bags compared with when they are directly dispersed in the medium. The objective of this study was to compare $\mathrm{CH}_{4}$ emission from different feeds measured using an in vitro method and incubated within filter bags or directly dispersed in the medium.

The study was conducted with the permission of the Swedish Ethical Committee on Animal Research. The details of the feed samples used in the current study and their chemical composition are reported by Krizsan et al. (2013). Eight feed samples were used: 4 concentrates and 4 forages. The 4 concentrates were barley, oat, canola meal, and dried sugar beet pulp; $\mathrm{CP}$ on a DM basis was $12.1,10.8,34.6$, and $10.1 \%$, respectively; and NDF concentration on a DM basis was 24.9, 35.5, 30.4 , and $31.7 \%$, respectively. The 4 forages were grass silage 1 (DM of $29.9 \%$ ) and grass silage 2 (DM of $31.4 \%$ ) of a mixed sward timothy (Phleum pratense L.) and meadow fescue (Festuca pratensis Huds.) harvested as a 
first cut (grass silage 1) and second cut (grass silage 2), respectively, a grass hay, and an alfalfa sample; $\mathrm{CP}$ on a DM basis was 15.0, 13.7, 10.2, and 19.1\%, respectively; and NDF concentration on DM basis was 56.6, 60.9, 61.3 , and $47.4 \%$, respectively. Samples were dried at $60^{\circ} \mathrm{C}$ for $48 \mathrm{~h}$ and ground through a $1.0-\mathrm{mm}$ screen using a cutting mill (Retsch SM 2000; Retsch GmbH, Haan, Germany) before the in vitro incubations.

Two Swedish Red cows were used as donor animals of rumen fluid $2 \mathrm{~h}$ after the morning feeding. The cows were fed a diet consisting of $60 \%$ grass silage and $40 \%$ concentrate on a DM basis. The rumen fluid was filtered through 2 layers of cheesecloth into preheated thermos flasks previously flushed with $\mathrm{CO}_{2}$ and further mixed with a buffer-mineral solution according to Menke and Steingass (1988). The in vitro procedure was performed as described by Krizsan et al. (2013). The ratio of rumen fluid to buffer was 1:2 and peptone (Merck KGaA, Darmstadt, Germany) was added to the buffer to supply the protein source for rumen microorganisms. Samples of $0.5 \mathrm{~g}$ were weighed directly in 250$\mathrm{mL}$ serum bottles (Schott, Mainz, Germany) or into F57 filter bags (for fiber and in vitro studies; Ankom Technology Corp., Macedon, NY) that were sealed and placed in the serum bottles. Samples were incubated in $60 \mathrm{~mL}$ of buffered rumen fluid and the bottles were then placed in a water bath at $39^{\circ} \mathrm{C}$ and gently and continuously agitated for $72 \mathrm{~h}$. All samples were incubated in 2 consecutive runs, including duplicate samples of blanks and standard hay; that is, each treatment was represented in 2 experimental units totally. To avoid any over-pressure in the bottles, the gases were released from the system at a preset pressure by the opening of an electric gas valve (approximately $1 \mathrm{~mL}$ of gas was released at each opening).

Measurement of $\mathrm{CH}_{4}$ emission was conducted as described by Ramin and Huhtanen (2012). In brief, gas samples were drawn using a gas-tight syringe $(1 \mathrm{~mL}$; Hamilton, Bonaduz, Switzerland) from each bottle at 24 and $48 \mathrm{~h}$ of incubation. Methane concentration was determined by injecting $0.2 \mathrm{~mL}$ of gas into a Varian Star 3400 CX gas chromatograph (Varian Analytical Instruments, Walnut Creek, CA) using thermal conductivity detection. Separation was achieved using a $1.8-\mathrm{m} \times$ 3.0-mm stainless steel HayeSep T 80/100 mesh column (Varian Analytical Instruments, Walnut Creek, CA) with argon as the carrier gas at a flow rate of $32 \mathrm{~mL} /$ min and an isothermal oven temperature of $32^{\circ} \mathrm{C}$. The injector and detector temperatures were set to $110^{\circ} \mathrm{C}$ and $135^{\circ} \mathrm{C}$, respectively. The peaks were identified and quantified by comparison with a standard gas mixture of $\mathrm{CO}_{2}(90 \mathrm{~mol} \%)$ and $\mathrm{CH}_{4}(10 \mathrm{~mol} \%)$ prepared by AGA Gas AB (Sundbyberg, Sweden). Other details and calculations of methane emission are given by Ra- min and Huhtanen (2012). Methane emission at each time point ( 24 or $48 \mathrm{~h}$ ) was calculated as $265 \times \mathrm{CH}_{4}$ concentration + total gas production $\times \mathrm{CH}_{4}$ concentration $\times 0.55$, where 265 is the total headspace volume in $\mathrm{mL}$ and 0.55 is the constant (the ratio of $\mathrm{CH}_{4}$ emission in the outflow gas from the in vitro system). Total gas production was measured with an automated system and the readings were done every $12 \mathrm{~min}$ and corrected to normal air pressure $(101.3 \mathrm{kPa})$ according to Cone et al. (1996). Mean blank gas production within run was subtracted from the sample gas production.

Methane emission was reported in milliliters per gram of DM, milliliters per gram of truly digested OM (TDOM; determined at $72 \mathrm{~h}$ of incubation), and as a proportion of the total gas recorded in the automated gas in vitro system.

The data were analyzed using the GLM procedure (release 9.2; SAS Institute Inc., Cary, NC) by applying the following model:

$$
Y_{i j k}=\mu+F_{i}+M_{j}+(F M)_{i j}+R_{k}+e_{i j k},
$$

where $Y_{i j k}=$ dependent variable, $\mu=$ overall mean, $F_{i}$ $=$ feed $i, M_{j}=$ method $j$, represented either by samples incubated directly dispersed in the medium or within filter bags in the gas in vitro system, $(F M)_{i j}=$ interaction between feed $i$ and method $j, R_{k}=$ run $k$, and $e_{i j k} \sim N\left(0, \sigma_{e}^{2}\right)$ is the random residual error. Least squares means are reported, and mean separation was done by least significant difference to test differences between treatments.

Methane emissions for all feeds at 24 and $48 \mathrm{~h}$ of incubation, incubated within filter bags or directly dispersed in the medium in the gas in vitro system, are presented in Table 1. Methane emission in milliliters per gram of DM was different between feeds at both 24 and $48 \mathrm{~h}$ of incubation $(P<0.01$; Table 1$)$. A significant feed $\times$ method interaction $(P<0.01$; Table 1) showed that $\mathrm{CH}_{4}$ emission was lower for barley, oat, and sugar beet pulp when incubated within filter bags compared with directly dispersed in the medium in the gas in vitro bottles $(P \leq 0.02)$. This was true at both time points except at $48 \mathrm{~h}$ of incubation for sugar beet pulp $(P=0.91)$. When $\mathrm{CH}_{4}$ emission was expressed in milliliters per gram of TDOM, $\mathrm{CH}_{4}$ emission was different between feeds at both 24 and $48 \mathrm{~h}$ of incubation $(P$ $<0.01$; Table 1). A significant feed $\times$ method interaction $(P<0.01$; Table 1$)$ showed that $\mathrm{CH}_{4}$ emission was higher for the grass silage and grass hay samples when incubated within filter bags compared with directly dispersed in the bottles at both 24 and $48 \mathrm{~h}$ of incubation $(P<0.01)$. We observed a weak relationship between $\mathrm{CH}_{4}$ emission $(\mathrm{mL} / \mathrm{g}$ of $\mathrm{DM}$ ) from feeds 
incubated in filter bags versus directly dispersed in the medium (Figure 1). Based on this, incubating feeds in bags is not a relevant method for ranking the feeds. The results were consistent with lower NDF and OM digestibility as well as lower total gas production when incubated in filter bags compared with the samples directly dispersed in the medium reported by Krizsan et al. (2013). Recently, Tagliapietra et al. (2012) reported lower NDF and DM digestibility of a wide range of feeds in vitro when the feeds were incubated in filter bags compared with those directly dispersed in the medium, suggesting lower microbial activity within bags. In addition, the degradation profiles of DM and NDF were underestimated when a wide range of forage samples incubated in F57 filter bags were placed in the rumen (Valente et al., 2011).The details of the mechanisms of the lower activity within bags are discussed by Krizsan et al. (2013). One reason could be the poor exchange of fluid inside the bags, resulting in an accumulation of VFA and consequently reducing the fibrolytic enzyme activity of the microorganisms attached to feed particles inside the bags. In general, incubating feeds in filter bags lowered the feed degradation and it was less accurate compared with in vivo degradation values (Krizsan et al., 2013).

The proportion of $\mathrm{CH}_{4}$ emission to total gas production did not differ between feeds $(P \geq 0.34$; Table 1$)$. A greater proportion of $\mathrm{CH}_{4}$ to total gas was produced across all feeds incubated within filter bags compared with samples directly dispersed in the medium at both time points of incubation $(P<0.01$; Table 1$)$. This

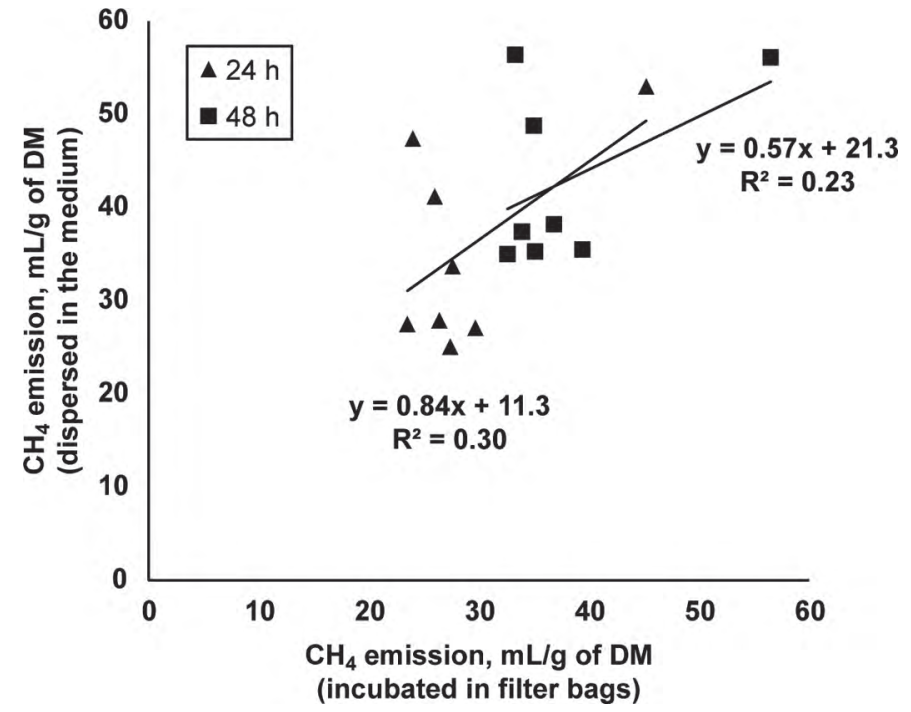

Figure 1. Relationship between $\mathrm{CH}_{4}$ emission (mL/g of DM) from feeds incubated in filter bags versus directly dispersed in the medium at 24 and $48 \mathrm{~h}$ of incubation (each symbol represents a feed sample).

suggests that, in addition to the difference in the extent of fermentation, the fermentation pattern also differed between the methods. The inconsistency reported in $\mathrm{CH}_{4}$ emission $(\mathrm{mL} / \mathrm{g}$ of $\mathrm{TDOM}$ ) indicates the biased measurement of $\mathrm{CH}_{4}$ emission when samples are incubated in filter bags compared with those directly dispersed in the medium. Greater $\mathrm{CH}_{4}$ emission $(\mathrm{mL} / \mathrm{g}$ of TDOM) for some grass samples incubated in filter bags compared with directly dispersed in the medium

Table 1. Methane emission at 24 and $48 \mathrm{~h}$ of incubation in milliliters per gram of DM, milliliters per gram of truly digested OM (TDOM), or as a proportion of total gas of the feed samples incubated directly dispersed in the medium or within filter bags in the gas in vitro system $(\mathrm{n}=2)$

\begin{tabular}{|c|c|c|c|c|c|c|c|c|c|c|c|c|}
\hline Item & Alfalfa & $\begin{array}{c}\text { Grass } \\
\text { silage } 1^{1}\end{array}$ & $\begin{array}{c}\text { Grass } \\
\text { silage } 2^{1}\end{array}$ & $\begin{array}{c}\text { Grass } \\
\text { hay }\end{array}$ & $\begin{array}{c}\text { Barley } \\
\text { grain }\end{array}$ & $\begin{array}{l}\text { Oat } \\
\text { grain }\end{array}$ & $\begin{array}{c}\text { Canola } \\
\text { meal }\end{array}$ & $\begin{array}{l}\text { Sugar } \\
\text { beet pulp }\end{array}$ & $\mathrm{SE}$ & \multicolumn{3}{|c|}{$P$-value ${ }^{2}$} \\
\hline Dispersed & 33.8 & 28.0 & 25.2 & 27.2 & 47.5 & 41.3 & 27.6 & 53.1 & \multirow[t]{2}{*}{2.19} & \multirow[t]{2}{*}{$<0.01$} & \multirow[t]{2}{*}{$<0.01$} & \multirow[t]{2}{*}{$<0.01$} \\
\hline Within bag & 27.6 & 26.4 & 27.4 & 29.7 & 24.0 & 26.0 & 23.5 & 45.2 & & & & \\
\hline \multicolumn{13}{|c|}{$\mathrm{CH}_{4}$ :Total gas at $24 \mathrm{~h}, \%$} \\
\hline \multicolumn{13}{|c|}{$\mathrm{CH}_{4}$ at $24 \mathrm{~h}, \mathrm{~mL} / \mathrm{g}$ of TDOM } \\
\hline Dispersed & 44.1 & 32.0 & 29.7 & 35.6 & 51.8 & 51.0 & 31.1 & 54.5 & \multirow[t]{2}{*}{3.10} & \multirow[t]{2}{*}{$<0.01$} & \multirow[t]{2}{*}{0.32} & \multirow[t]{2}{*}{$<0.01$} \\
\hline Within bag & 38.0 & 38.5 & 48.0 & 50.0 & 28.5 & 36.4 & 28.0 & 49.7 & & & & \\
\hline \multicolumn{13}{|c|}{$\mathrm{CH}_{4}$ at $48 \mathrm{~h}, \mathrm{~mL} / \mathrm{g}$ of $\mathrm{DM}$} \\
\hline Dispersed & 38.2 & 37.4 & 35.3 & 35.5 & 56.4 & 48.8 & 35.0 & 56.1 & \multirow[t]{2}{*}{2.48} & \multirow[t]{2}{*}{$<0.01$} & \multirow[t]{2}{*}{$<0.01$} & \multirow[t]{2}{*}{$<0.01$} \\
\hline Within bag & 36.8 & 33.9 & 35.1 & 39.4 & 33.3 & 35.0 & 32.6 & 56.5 & & & & \\
\hline \multicolumn{13}{|c|}{$\mathrm{CH}_{4}$ :Total gas at $48 \mathrm{~h}, \%$} \\
\hline
\end{tabular}

${ }^{1}$ Grass silage 1 and 2 were harvested as first and second cut, respectively.

${ }^{2}$ Probability of a significant effect of feed, method, and interaction between feed and method $(\mathrm{F} \times \mathrm{M})$. 
reflects different fermentation patterns, as indicated by the higher $\mathrm{CH}_{4}$ to total gas ratio. For barley and oats samples, lower $\mathrm{CH}_{4}$ emission when the samples were incubated in filter bags can be an overestimation of TDOM. Rather than being truly fermented in vitro, some nonfiber OM could have been solubilized during neutral detergent extraction from the residues after in vitro incubations, as the greater difference in total gas production from the feeds compared with TDOM suggests this discrepancy (Krizsan et al., 2013).

The in vitro method used in the current study for methane measurements has been used for determination of $\mathrm{CH}_{4}$ emission from various feed samples successfully. Recently, Ramin et al. (2011) reported that concentrate level (40:60 vs. 60:40, barley:grass silage) resulted in no significant difference in $\mathrm{CH}_{4}$ emission when nutshell extract (a $\mathrm{CH}_{4}$ inhibitor) was used in vitro. The results obtained in the current study showed differences in $\mathrm{CH}_{4}$ emission between concentrates and forages. Our results are in line with the study of Moss et al. (1995), who reported an increase in $\mathrm{CH}_{4}$ emission relative to the gross energy of the diet when the level of barley in grass silage diets fed to sheep was increased. However, in the current study, concentrate was incubated as a sole feed and cannot be regarded truly representative of practical conditions. The high $\mathrm{CP}$ concentration of canola meal in the current study $(34.6 \%)$ could explain the lower value of $\mathrm{CH}_{4}$ emission compared with other concentrates. Moss and Givens (2002) showed a decrease in $\mathrm{CH}_{4}$ emission (in $\mathrm{L} / \mathrm{d}$ ) when the level of soybean meal fed to sheep at close to maintenance level increased. In contrast, a high amount of $\mathrm{CH}_{4}$ was produced when sugar beet pulp was incubated in vitro, which is in line with the findings reported by Hindrichsen et al. (2004) of enhanced in vitro $\mathrm{CH}_{4}$ emission from diets with high sugar content.

Methane emission was lower when the samples were incubated in filter bags compared with when they were directly dispersed in the medium because of reduced substrate fermentation in the in vitro system. However, the proportion of $\mathrm{CH}_{4}$ to total gas production was greater for samples incubated in filter bags compared with feeds directly dispersed in the medium. This is likely an indication of altered microbial population or fermentation pattern of the samples incubated in bags compared with those directly dispersed in the in vitro bottles. The significant interaction between feed and method showed that the ranking of methane output for different feeds changed because of the method. The results of this study indicate that incubating feed samples in filter bags in vitro is not appropriate when measuring $\mathrm{CH}_{4}$ emission during $48 \mathrm{~h}$ of incubation.

\section{ACKNOWLEDGMENTS}

F. Jančík was supported by the Ministry of Agriculture of the Czech Republic (Project No. MZE0002701404).

\section{REFERENCES}

Becker, P. M., and P. G. van Wikselaar. 2011. Effects of plant antioxidants and natural vicinal diketones on methane production, studied in vitro with rumen fluid and a polylactate as maintenance substrate. Anim. Feed Sci. Technol. 170:201-208.

Cederberg, C., F. Hedenus, S. Wirsenius, and U. Sonesson. 2013 Trends in greenhouse gas emissions from consumption and production of animal food products-Implications for long-term climate targets. Animal 7:330-340.

Cone, J. W., A. H. Van Gelder, G. J. W. Visscher, and L. Oudshoorn. 1996. Influence of rumen fluid and substrate concentration on fermentation kinetics measured with a fully automated time related gas production apparatus. Anim. Feed Sci. Technol. 61:113-128.

Hindrichsen, I. K., H. R. Wettstein, A. Machmuller, C. R. Soliva, K. E. Bach Knudsen, J. Madsen, and M. Kreuzer. 2004. Effects of feed carbohydrates with contrasting properties on rumen fermentation and methane release in vivo. Can. J. Anim. Sci. 84:265-276.

Johnson, K. A., and D. E. Johnson. 1995. Methane emissions from cattle. J. Anim. Sci. 73:2483-2492.

Krizsan, S. J., F. Jančík, M. Ramin, and P. Huhtanen. 2013. Comparison of some aspects of the in situ and in vitro methods in evaluation of neutral detergent fiber digestion. J. Anim. Sci. 91:838 847. http://dx.doi.org/10.2527/jas.2012-5343.

Menke, K. H., and H. Steingass. 1988. Estimation of the energetic feed value obtained from chemical analysis and in vitro gas production using rumen fluid. Anim. Res. Dev. 28:7-25.

Moss, A. R., and D. I. Givens. 2002. The effect of supplementing grass silage with soya bean meal on digestibility, in sacco degradability, rumen fermentation and methane production in sheep. Anim. Feed Sci. Technol. 97:127-143.

Moss, A. R., D. I. Givens, and P. C. Garnsworthy. 1995. The effect of supplementing grass silage with barley on digestibility, in sacco degradability, rumen fermentation and methane production in sheep at two levels of intake. Anim. Feed Sci. Technol. 55:9-33.

Nozière, P., and B. Michalet-Doreau. 2000. In sacco methods. Pages 233-253 in Farm Animal Metabolism and Nutrition. J. P. F. D'Mello, ed. CABI Publishing, Wallingford, UK.

Opsi, F., R. Fortina, S. Tassone, R. Bodas, and S. López. 2012. Effects of inactivated and live cells of Saccharomyces cerevisiae in in vitro ruminal fermentation of diets with different forage:concentrate ratio. J. Agric. Sci. 150:271-283.

Ramin, M., M. Griinari, and P. Huhtanen. 2011. Determination of ruminal methane production using a fully automated in vitro gas system-A modelling approach. Adv. Anim. Biosci. 2:272.

Ramin, M., and P. Huhtanen. 2012. Development of an in vitro method for determination of methane production kinetics using a fully automated in vitro gas system-A modelling approach. Anim. Feed Sci. Technol. 174:190-200.

Ramin, M., and P. Huhtanen. 2013. Development of equations for predicting methane emissions from ruminants. J. Dairy Sci. 96:24762493. http://dx.doi.org/10.3168/jds.2012-6095.

Sakthivel, P. C., D. N. Kamra, N. Agarwal, and L. C. Chaudhary. 2012. Effect of sodium nitrate and nitrate reducing bacteria on in vitro methane production and fermentation with buffalo rumen liquor. Asian-australas. J. Anim. Sci. 25:812-817.

Tagliapietra, F., M. Cattani, I. K. Hindrichsen, H. H. Hansen, S. Colombini, L. Bailoni, and S. Schiavon. 2012. True dry matter digestibility of feeds evaluated in situ with different bags in vitro using rumen fluid collected from intact donor cows. Anim. Prod. Sci. $52: 338-346$.

Valente, T. N. P., E. Detmann, A. C. Queiroz, S. C. Valadares Filho, D. I. Gomes, and J. F. Figueiras. 2011. Evaluation of ruminal degradation profiles of forages using bags made from different textiles. Braz. J. Anim. Sci. 40:2565-2573. 